\title{
Proporsi dan Alasan Pengunaan Buah Lokal dan Non Lokal Bali dalam Upacara Keagamaan Pura Kahyangan Tiga di Desa Pakraman Sebali Kecamatan Tegallalang, Kabupaten Gianyar
}

\author{
I WAYAN YOGA WIRA SAPUTRA, I DEWA PUTU OKA SUARDI, \\ WAYAN WINDIA \\ Program Studi Agribisnis, Fakultas Pertanian, Universitas Udayana \\ Jl. PB. Sudirman Denpasar 80323, Bali \\ Email : wirasaputrayoga@gmail.com \\ okasuardi@unud.ac.id
}

\begin{abstract}
Proportion and Reasons of Using Bali's Local and Non Local Fruits in Religious Ceremony of Pura KahyanganTiga in the Pakraman Village of Sebali, Tegallalang Sub-District of Gianyar Regency
\end{abstract}

Pakraman Village of Sebali is a village located in Keliki Village, Tegallalang Subdistrict, of Gianyar Regency. The number of non-local fruits affect the use of fruits in the religious ceremonies in Pakraman Village of Sebali. The purpose of this study was to investigate the reasons for the use of local and non-local fruits as a means of religious rituals in the Pakraman Village of Sebali. The use of local and non-local Balinese fruits in Sebali Pakraman Village, Tegallalang Subdistrict, Gianyar regency, with the average comparison of the total use of local fruit with non-local Bali fruit per $\mathrm{kg}$ was 14.72: 13 with average price comparison of 208.059: 465.930 or $53.08 \%$ : $46.88 \%$. With the use of fruits in each temple, namely, Pura Desa for $7.5 \mathrm{~kg}$ with a value of $\mathrm{Rp} 104.699$ for local fruit, and $6.42 \mathrm{~kg}$ with a value of $\mathrm{Rp} 223.263 .3$ for nonlocal fruit. Pura Puseh by $3.23 \mathrm{~kg}$ with value Rp 42.889,3 for local fruit and $3.03 \mathrm{~kg}$ with value Rp 108.000 for non-local fruits. Pura Dalem by $3.99 \mathrm{~kg}$ with a value of Rp 55,099 for local fruits and $3.56 \mathrm{~kg}$ with a value of $\mathrm{Rp} \mathrm{134,666.} \mathrm{Housewives} \mathrm{are}$ expected to encourage the development of local fruit cultivation and support local fruit farmers.

Keywords: proportion, reason, local fruits, non-local fruits, Sebali Pakraman Village

\section{Pendahuluan}

\subsection{Latar Belakang}

Indonesia dengan ribuan pulaunya menyimpan kekayaan sumber daya hayati, terutama buah tropika beserta komponen genetik pendukungnya yaitu mikroorganisme tanah, serangga polinator dan musuh alami. Tidak kurang dari 329 jenis buah-buahan, baik yang merupakan jenis asli Indonesia maupun introduksi, dapat ditemukan di 
Indonesia. Banyaknya produk buah non lokal yang masuk tentunya mempengaruhi minat masyarakat terhadap penggunaan buah non lokal, sesuai data yang diperoleh dari Warta ekspor tahun 2016 impor bua-buahan sebanyak 711.519 ton (Warta Ekspor, 2017). Menurut Rivai (1986), tidak kurang dari 329 jenis buah-buahan (terdiri dari 61 suku dan 148 marga) baik yang merupakan jenis asli Indonesia maupun pendatang (introduksi) yang telah ditemukan di Indonesia, sementara menurut Verheij dan Coronel (1992) di kawasan Asia Tenggara terdapat sekitar 400 jenis buah-buahan yang dapat dimakan, dari tiga perempat jenis buah-buahan yang dilaporkan terdapat di kawasan Asia Tenggara tersebut telah ditemukan di Indonesia.

Buah buahan tersebut telah menggeser paradigma masyarakat lokal Bali akan adanya buah lokal yang tidak kalah secara kualitas dan kuantitas dengan buah impor tersebut. Proporsi dalam penelitian ini adalah keseimbangan penggunaan buah buahan lokal dan non lokal di Desa Pakraman Sebali, Kecamatann Tegallalang, Kabupaten Gianyar. Alasan adalah proses penyampaian kesimpulan dari data pemikiran yang membenarkan gerakan dari data menuju kesimpulan. Alasan dalam penelitian ini adalah kesimpulan masyarakat dalam menggunakan buah lokal atau non lokal dalam upacara keagamaan di Desa Pakraman Sebali, Kecamatan Tegallalang, Kabupaten Gianyar. Pelaksanaanya dilakukan melalui aktifitas upacara, karena melalui upacara, orang Hindu diharapkan tidak melupakan lingkungan bahkan harus menyatu dengan lingkungan untuk mewujudkan kebahagiaan hidup (Gunung, 2004 dalam Darma, 2012).

\subsection{Rumusan Masalah}

Berdasarkan latar belakang masah yang sudah dijelaskan sebelumnya dapat dirumuskan masalah sebagai berikut.

1. Bagaimana proporsi penggunaan buah lokal dan buah non lokal Bali sebagai sarana upacara keagamaan di Desa Pakraman Sebali

2. Apa alasan penggunaan buah lokal dan buah buah non lokal Bali sebagai sarana upacara keagaman di Desa Pakraman Sebali

\subsection{Tujuan Penelitian}

Adapun tujuan penelitian ini sebagai berikut.

1. Mengetahui proporsi penggunaan buah lokal dan buah non lokal Bali sebagai sarana upacara keagamaaan di Desa Pakraman Sebali.

2. Mengetahui alasan penggunaan buah lokal dan buah non lokal Bali sebagai sarana upacara keagamaan di Desa Pakraman Sebali.

\section{Metode Penelitian}

\subsection{Lokasi dan Waktu Penelitian}

Lokasi penelitian adalah dilakukan di Desa Pakraman Sebali, Kecamatan Tegallalang, Kabupaten Gianyar. Pemilihan lokasi penelitian ini dilakukan secara sengaja, dengan dasar pertimbangan tertentu sebagai berikut.

1. Dominasi penggunaan buah non lokal dalam upacara keagamaan.

2. Buah non lokal lebih diminati dari pada buah lokal

3. Wilayah penelitian yang mudah dijangkau.

4. Belum pernah dilakukan penelitian serupa di Desa Pakraman Sebali. 
Penelitian ini dilaksanakan selama tiga bulan yaitu mulai dari bulan Agustus sampai dengan Desember 2017.

\subsection{Populasi dan Sampel}

Populasi adalah wilayah yang terdiri atas objek/subyek yang mempunyai kualitas dan karakterisik tertentu yang diterapkan oleh peneliti untuk dipelajari dan kemudian ditarik kesimpulannya (Sugiyono, 2010). Populasi dalam penelitian ini adalah seluruh ibu rumah tangga yang ada di Desa Pekraman Sebali, Kecamatan Tegallalang, Kabupaten Gianyar yang berjumlah 268 orang. Sampel dari penelitian ini adalah 30 orang ibu rumah tangga.

\subsection{Data Penelitian}

Jenis data yang dipergunakan dalam penelitian ini meliputi data kualitatif dan data kuantitatif.

1. Data kualitatif adalah data yang berbentuk kata, penjelasan, skema dan gambaran yang tidak dapat dihitung dengan satuan hitung (Sugiyono, 2010). Penelitian ini data kualitatif menjelaskan mengenai, bagaimana proporsi dan alasan penggunaan buah lokal dan non lokal Bali.

2. Data kuantitatif yaitu data yang berupa angka-angka dan dapat dihitung (Sugiyono, 2010). Data yang dapat dihitung dan dalam bentuk angka-angka dengan satuan tertentu (Sugiyono, 2010). Penelitian ini data kuantitatif diperoleh dengan data kuantitaif mengenai tingkat proporsi penggunaan buah lokal dan non lokal Bali di Desa Pakraman Sebali dari hasil kuisioner penelitian.

Sumber data yang dipergunakan dalam penelitaian ini mencakup data primer dan sekunder sebagai berikut.

1. Data primer adalah sumber data yang diperoleh secara langsung dari sumber aslinya (Maulidi, 2016). Data primer dalam penilitian ini berupa jawaban responden terhadap pertanyaan yang diajukan melalui kuisioner dan wawancara terhadap penggunaan buah lokal dan impor di Desa Pakraman Sebali meliputi jumlah penggunaan buah dalam kilogram serta nilai penggunaan buah dalam rupiah.

2. Data sekunder dalam penelitian ini berupa jumlah penduduk, luas wilayah, dan kondisi geografi di Desa Parakaman Sebali.

\subsection{Metode Pengumpulan Data}

1. Wawancara (interview) adalah teknik pengumpulan data dengan mengajukan pertanyaan langsung oleh pewawancara kepada responden dan jawaban-jawaban responden yang dicatat atau direkam (Hasan, 2002).

2. Wawancara mendalam (indepth interview). Menurut Moleong, (2005) wawancara mendalam merupakan proses menggali informasi secara mendalam, terbuka, dan bebas dengan masalah dan fokus penelitian dan diarahkan pada pusat penelitian. Penelitian ini wawancara mendalam diberikan kepada Kelihan Adat Desa Pakraman Sebali, dan Kelihan Dinas Desa Sebali menggunakan instrumen pedoman. Wawancara mendalam (indepth interview) yang dilengkapi dengan 
daftar pertanyaan yang berhubungan dengan penggunaan buah lokal dan non lokal Bali sebagai sarana upacara keagamaan di Desa Pakraman Sebali.

3. Observasi adalah teknik pengumpulan data yang dilakukan dengan pengamatan secara langsung pada objek penelitian yakni pengamatan langsung pada daerah penelitian dengan melihat secara langsung penggunaan buah dalam banten sebagai sarana upacara keagamaan di Desa Pakraman Sebali selama periode penelitian.

\subsection{Instrumen Pengumpulan Data}

Instrumen penelitian yang digunakan dalam penelitian ini yaitu kuisioner. Kuesioner merupakan serangkaian atau daftar pernyataan yang disusun sistematis, kuesioner diisi oleh responden dan dikembalikan kepada peneliti (Bungin, 2006).

\subsection{Batasan Operasional}

Batasan operasional pada penelitian ini sebagai berikut.

1. Proporsi adalah perbandingan nilai penggunaan buah lokal dan buah non lokal Bali.

2. Alasan adalah sikap yang diambil masyarakat dalam menggunakan buah buahan sebagai sarana upacara keagamaan.

3. Buah lokal adalah buah-buahan yang hidup, tumbuh dan verietasnya tanaman asli Indonesia.

4. Buah non lokal Bali adalah buah yang didatangkan dari luar negeri.

5. Konsumsi adalah proporsi penggunaaan buah yang digunakan sebagai sarana upacara keagamaan di Desa Pakraman Sebali.

\subsection{Analisis Data}

Metode analisis data yang digunakan dalam penelitian ini adalah analisis deskriptif kualitatif yaitu dilihat bagaimana proporsi nilai penggunaan masyarakat terhadap buah lokal dan buah non lokal Bali, dan alasan penggunaan buah lokal dan buah non lokal Bali untuk upacara keagamaaan.

\section{Gambaran Umum Lokasi Penelitian}

\subsection{Karakteristik Responden}

Jumlah responden dalam penelitian ini adalah sejumlah 30 orang ibu rumah tangga. Berusia diantara 20 sampai 60 tahun dengan tingkat pendidikan mulai dari sekolah dasar (SD) sampai dengan tingkat sarjana dan pekerjaan yang beragam seperti, sebagai ibu rumah tangga, karyawan, dan petani.

\subsection{Usia Responden}

Berdasarkan hasil dari tabulasi kuisioner dapat diperoleh karakteristik responden untuk kelompok usia responden tertinggi yaitu usia 26 sampai 30 tahun (27\%) dan yang terendah usia 55 sampai 60 tahun (3\%). 


\subsection{Pendidikan Responden}

Berdasarkan hasil penelitian tingkat pendidikan masyarakat Desa Pakraman Sebali tergolong sedang. Tingkat pendidikan responden rata-rata menempuh pendidikan menengah atas ( SMA).

\subsection{Pekerjaan Responden}

Sebagian besar responden memiliki pekerjaan sebagai ibu rumah tangga dengan jumlah 19 orang responden $(63 \%)$.

\subsection{Jumlah Anggota Keluarga Responden}

Jumlah responden yang mempunyai anggota keluarga 3 orang adalah yang terbanyak yaitu 18 responden $(60 \%)$.

\section{Hasil dan Pembahasan}

\subsection{Proporsi Penggunaan Buah Lokal dan Buah Non Lokal Bali}

Berdasarkan hasil penelitian, penggunaan buah-buahan lokal dan non lokal Bali di Desa Pakraman Sebali, Kecamatan Tegallalang, Kabupaten Gianyar yakni, sejumlah $27,73 \mathrm{~kg}$ dengan nilai total rata-rata penggunaan keseluruhan buah Rp 673.989, meliputi 14,72 kg buah lokal dengan nilai Rp 208.059 dan $13 \mathrm{~kg}$ buah non lokal Bali dengan nilai $\mathrm{Rp}$ 465.930. Berdasarkan total rata-rata penggunaan buah tersebut membuktikan bahwa penggunaan buah lokal di Desa Pakraman Sebali lebih tinggi dibandingkan penggunaan buah non lokal Bali dengan selisih penggunaan 1,72 $\mathrm{kg}$ lebih banyak buah lokal yang dipergunakan oleh responden.

\subsubsection{Penggunaan buah lokal dan non lokal di Pura Desa}

Pengunaan buah lokal di Pura Desa sebanyak 7.5 kg dengan nilai Rp 104.669. Penggunaan buah lokal Bali terbanyak adalah jenis buah mangga dengan rata-rata pengguaan buah sebanyak $1.65 \mathrm{~kg}$ dengan nilai penggunaan $\mathrm{Rp} 19.800$. Penggunaan buah lokal terendah adalah jenis buah manggis dan rambutan sejumlah $0,10 \mathrm{~kg}$ dengan nilai Rp 1000 untuk rambutan dan Rp 3000 untuk manggis. Total penggunaan buah non lokal di Pura Desa sebanyak 6,42 kg dengan total nilai Rp 223.263,3. Penggunaan buah terbanyak adalah jenis buah pir sebanyak $1.33 \mathrm{~kg}$ dengan nilai Rp 13.333.

\subsubsection{Penggunaan buah lokal dan non lokal Bali di Pura Puseh}

Pengunaan buah lokal di Pura Puseh sebanyak 3,23 kg dengan nilai $\mathrm{Rp}$ 428.899,3. Penggunaan buah lokal Bali terbanyak adalah jenis buah mangga dengan rata-rata pengguaan buah sebanyak $0,8 \mathrm{~kg}$ dengan nilai penggunaan $\mathrm{Rp}$ 9.600. Selanjutnya untuk total penggunaan buah non lokal di Pura Puseh sebanyak 3,03 kg dengan total nilai Rp 108.000. Penggunaan buah terbanyak adalah jenis buah anggur merah sebanyak 0,6 kg dengan nilai Rp 36.000. Sedangkan untuk penggunaan buah non lokal yang paling rendah adalah jenis buah jeruk shantang sebanyak 0,07 kg dengan nilai $\operatorname{Rp} 2.000$. 


\subsubsection{Penggunaan buah lokal dan non lokal Bali di Pura Dalem}

Pengunaan buah lokal di Pura Puseh sebanyak 3,99 kg dengan nilai Rp 55. 099. Penggunaan buah lokal Bali terbanyak adalah jenis buah pisang dengan rata-rata penggunaan buah sebanyak $0,83 \mathrm{~kg}$ dengan nilai penggunaan $\mathrm{Rp}$ 8.333. Total penggunaan buah non lokal di Pura Dalem sebanyak 3,56 kg dengan total nilai $\mathrm{Rp}$ 134.666. Penggunaan buah terbanyak adalah jenis buah anggur merah sebanyak $0,80 \mathrm{~kg}$ dengan nilai $\mathrm{Rp}$ 48.000. Penggunaan buah non lokal yang paling rendah adalah jenis buah kiwi sebanyak 0,03 kg dengan nilai Rp 2.000 .

\subsection{Alasan Penggunaan Buah Lokal dan Non Lokal Bali dalam Upacara Keagamaan}

Penggunaan buah lokal ibu rumah tangga di Desa Sebali sebagian besar memberikan alasan bahwa harga buah lebih murah, dimana dari 30 orang ibu rumah tangga 20 responden memberikan alasan tersebut 66,7\%. Sebanyak 20\% orang responden memberikan alasan bahwa rasa buah lokal lebih enak, 3,3\% responden memberikan alasan warna buah lebih cerah, $13,3 \%$ orang responden memberikan alasan buah lokal lebih awet dan 3,3\% orang responden memberikan alasan bahwa buah lokal lebih sehat.

Alasan pengunaan buah non lokal di Desa Pakraman Sebali dari 30 orang ibu rumah tangga 21 responden memberikan alasan warna buah non lokal Bali lebih cerah $70 \%$. 13,3\% responden memberikan alasan rasa buah non lokal lebih enak, dan 23,3\% responden memberikan alasan buah non lokal lebih awet.

\section{Simpulan dan Saran}

\subsection{Simpulan}

Berdasarkan hasil penelitian dan pembahasan maka dapat ditarik beberapa simpulan sebagai berikut.

1. Rata-rata penggunaan buah dalam upacara keagamaan Pura Kahyangan Tiga di Desa Pakraman Sebali sebanyak 27,73 kg dengan nilai Rp 673.989,00, dengan proporsi 14,72 $\mathrm{kg}(53,08 \%)$ buah lokal senilai Rp 208.059,00 (30,87\%) dan $13 \mathrm{~kg}$ (46,88\%) buah non lokal Bali dengan nilai Rp 465.930,00 (69,13\%).

2. Alasan penggunaan buah lokal dalam upacara keagamaan Pura Kahyangan Tiga di Desa Pakraman Sebali yakni : harga lebih murah (66,6\%); rasa lebih enak $(20 \%)$; lebih awet $(13,3 \%)$; warna lebih menarik (3,3\%); dan lebih bergizi $(3,3 \%)$. Sedangkan alasan penggunaan buah non lokal meliputi: warna lebih menarik $(70 \%)$; lebih awet $(23,3 \%)$; dan rasa lebih enak $(13,3 \%)$.

\subsection{Saran}

Berdasarkan hasil penelitian, maka dapat diberikan saran adalah sebagai berikut.

1. Ibu rumah tangga agar lebih mengoptimalkan dalam penggunaan buah lokal untuk menghemat pengeluaran biaya, disamping untuk mendorong berkembangnya budidaya buah-buahan lokal. 
2. Pemerintah daerah diharapkan membuat regulasi yang mengatur tentang masuknya buah impor agar peluang konsumsi atau penggunaan buah lokal lebih tinggi dari buah non lokal Bali.

\section{Ucapan Terimakasih}

Terimakasih kepada semua pihak yang telah memberikan bantuan berupa data, buah fikiran, kebendaan dan lain-lain sehingga e-jurnal ini dapat diselesaikan dengan baik. Semoga hal didalamnya bermanfaat adanya.

\section{Daftar Pustaka}

Burhan Bungin. 2006. Analisis Data Penelitian Kualitatif. Raja Grafindo. Jakarta.

Gunung, M.G. Ida Pedanda. 2004. Sambutan Ketua PHDI Bali-Seminar Tumbuhan Upacara Agama Hindu Bali LIPI. Jakarta.

Hasan, M. Iqbal, Pokok-pokok Materi Metodologi Penelitian dan Aplikasinya, Ghalia Indonesia, Bogor, 2002.

Lexy J. Moleong. 2005. Metodologi Penelitian Kualitatif, Remaja Rosdakarya. Bandung.

Maulidi, Achmad. 2016. Pengertian Data Primer dan Data Sekunder. https://www.kanalinfo.web.id/2016/10/pengertian-data-primer-dan-sekunder.html (diakses pada tanggal 18 Januari 2017).

Rivai, M.A. 1986. Flora Buah-Buahan Indonesia. Lembaga Biologi Nasional-LIPI. Bogor.

Sugiono. 2010. Metode Penelitian Pendidikan: Pendekatan Kuantitatif, Kualitatif dan $R$ \& D. Alfabeta. Bandung.

Sunaryono, H. 2013. Berkebun 26 Jenis Tanaman Buah. Penerbit:Penebar Swadaya. Jakarta.

Verheij, E.W.M, dan E.E. Coronel. 1994. Buah-buahan yang Dapat Dimakan (Prosea Sumber Daya Nabati Asia Tenggara 2). PT. Gramedia Pustaka Utama. Jakarta.

Warta Ekspor. 2017. Potensi ekspor buah tropis Indonesia. [Online]. Tersedia: http://djpen.kemendag.go.id/appfrontend/admin/docs/publication/.4261519022554 .pdf\&ved=2ahUKEwjlucuh1 vraAhURo8KHQWPArwQFjaDegQIAxAB\&usg=A OvVaw1u6w0JyBoe7WCe8SScR 